\title{
Social class, epileptic activity, and disadvantage at work
}

\author{
GRAHAM SCAMBLER \\ From the Academic Department of Psychiatry, Middlesex Hospital Medical School, London
}

\author{
ANTHONY HOPKINS \\ From the Department of Neurological Sciences, St. Bartholomew's Hospital, London
}

SUMmARY A community sample of 94 adults with epilepsy were interviewed in their homes by a sociologist and a neurologist. Less than half of those who had worked full-time after the onset of their seizures could recall that their careers had been inhibited by their epilepsy, yet most felt 'at risk' and chose to conceal their condition from their employers or potential employers. Disadvantage in employment was found to be related both to a working class status and to a high rate of epileptic activity. We suggest that epileptics are prone to deny themselves career opportunities.

It is now widely acknowledged that people with epilepsy are as likely to be distressed by social and cultural problems as they are by continuing seizures. ${ }^{1}$ Such problems are held to be especially common among those at work or looking for work. It has been estimated that there are about 140000 epileptics in the employment market and that about 13000 join the labour force every year. ${ }^{2}$ Different studies have set the proportion who experience employment problems at between one-quarter and three-quarters of the total of $140000 .{ }^{34}$ We were concerned, firstly, to examine the current employment status of a sample of adults with epilepsy; secondly, to discover the extent to which they had concealed their epilepsy from employers; and, thirdly, to learn something of the causes of any work problems they had encountered. This investigation was part of a more comprehensive study of what it is like to be an epileptic in our society.

\section{Methods}

Our study focused on adults living in the community. We identified all those who, on prevalence day, (a) were aged 16 or over, (b) had had more than one non-febrile seizure of any type, (c) had had at least one seizure in the preceding two years and/or had been on continuing anticonvulsant drugs for more than one non-febrile seizure in the past, (d) were not in long-term institutional care, and (e) were present in a population of 42339 registered with 17 general practitioners in five group practices in and around London. Of this population, 32020 (76\%) were aged 16 or over. One hundred and eight people satisfied our restrictive criteria, giving a prevalence of 340 per 100000 . Ninety-four of the $108(87 \%)$ consented to domiciliary interviews with a sociologist and a neurologist. We have no reason to believe that the 94 people interviewed were not representative of people with diagnosed epilepsy in the community. Information about the 14 who declined to participate indicated that they did not differ appreciably from those interviewed in terms of sex, age, marital status, employment status, social class, type of seizure, or frequency of seizures. The material in this paper is derived exclusively from the interviewed sample.

The collection and analysis of the medical data have been discussed in detail elsewhere. ${ }^{5}$ The material obtained by the sociologist covered most stages in what might be termed the 'career' of the epileptic-from the initial awareness of symptoms to the day-to-day accommodation of the label 'epileptic'. Special attention was paid to (a) the importance of the medical community as a patient reference group, (b) the supportive role of the family, (c) actual and potential crises in employment, and (d) changes in self-perceptions. It is with (c) that we are concerned here. The interviews were recorded and the data were either translated directly onto previously formulated rating scales or transcribed on 
a series of cross-referenced 'topic cards' which in time yielded additional, more complex rating scales (for example, on the timing and fullness of disclosures to employers).

\section{Results}

CURRENT EMPLOYMENT STATUS

Nearly all those we asked were aware that epilepsy can inhibit a person's opportunities for work. ${ }^{5} \mathrm{We}$ were therefore interested to find out how those we interviewed were themselves faring. We looked first at their current employment status. Forty-two out of $73(58 \%)$ of those of working age who were not engaged in any form of further education were in full-time employment at the time of interview: that is, 31 out of $42(74 \%)$ of the men; six out of $19(32 \%)$ of the married women; and five out of $12(42 \%)$ of the unmarried women. The equivalent proportions for the general population of Britain in 1975 were $81 \%$ (men); $48 \%$ (married women); and $42 \%$ (unmarried women). ${ }^{6}$ Three people in the sample were working part-time.

Social class distributions for the 42 in full-time work, the total sample of 94 , and the total household population of England and Wales in 1971 are shown in the Figure. In common with those in other studies

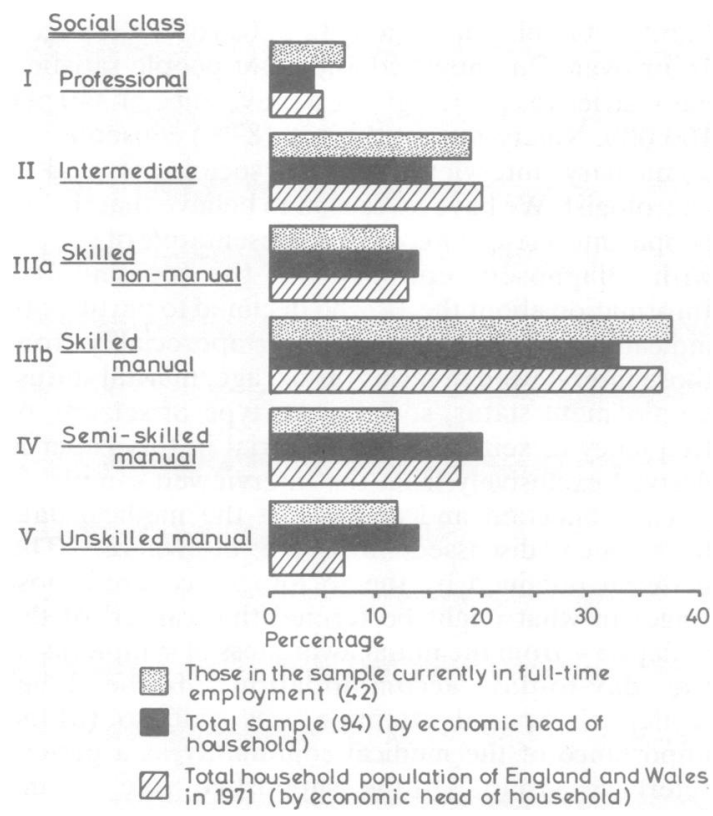

Figure Social class distributions for the 42 people in the sample who were in full-time employment, the total sample of 94, and the total household population of England and Wales in 1971. of epileptics in the community, these social class $\frac{\overline{0}}{\circ}$ distributions show that the working classes are slightly over-represented, ${ }^{7}$ but this may be entirely due to an imbalance in the general practice populations from which the sample was drawn. There was no evidence of intragenerational 'social drift' downwards from one class to another as a result of $\frac{1}{\mathbb{D}}$ epilepsy. ${ }^{8}$ There was some association, however, between social class and current employment status. Our measure of the former was derived from the Registrar General's Classification of Occupations, $\bar{\partial}$ and for present purposes we have taken the Registrar $\frac{}{0}$ General's Social Classes I, II, and IIIa as constituting $\overline{\overline{0}}$ the middle class and IIIb, IV, and V the working $\mathbb{D}$ class. Twenty-one out of $28(75 \%)$ of those who were unemployed were from working class and ${ }^{\infty}$ $25 \%$ from middle class households; among those in $\vec{\circ}$

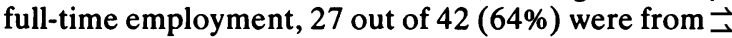
working class and $36 \%$ from middle class households. $\omega$

There was a much stronger independent association between seizure frequency and current $\stackrel{5}{\%}$ employment status. Nine out of $28(32 \%)$ of the $\omega$ unemployed were having generalised seizures more iv often than monthly at the time of interview, but on $\Phi_{j} \vec{\sim}$ one out of $42(2 \%)$ of the employed $(P<0 \cdot 001)$. Thos $c$ relationship held equally true for partial seizures: out of $28(43 \%)$ of the unemployed wewexperiencing partial seizures more often tha्n $\subseteq$ monthly, compared with three out of $42(7 \%)$ of t employed $(P<0.001)$. All the six people who we $\overrightarrow{0}$ having both generalised and partial seizures mol $\infty$ often than monthly were unemployed. Anybody in. the sample who was having either generalised or partial seizures more often than monthly, and who also came from a working class household, stood very little chance of being in full-time work: thus, all the $\stackrel{0}{\circ}$

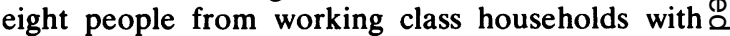
generalised seizures more often than monthly were $\overrightarrow{\vec{O}}$ unemployed, compared with one of the two people 3 from middle class households. Similarly, eight of the $\bar{T}$ nine from working class households with partialo seizures more often than monthly were unemployed, compared with three of the six from middle class $?$ households.

\section{DISCLOSURES TO EMPLOYERS}

Given the widespread belief that epilepsy can impede people's careers, and the almost equally widespreado conviction that it is a stigmatising condition, it is perhaps not surprising that many in the sample were음 reluctant to disclose their epilepsy to their employers. Twenty-one out of 40 , or more than half, of those $N$ who had had two or more full-time jobs after onset of N their seizures had never disclosed their epilepsy to an N employer, and only four out of 40 , or one in 10 , had ${ }^{\omega}$ always disclosed it. For the 42 people in full-time 
work at the time of the interview, we have complete information for 40 on the fullness, timing, and circumstances of any disclosures made. Twenty-two out of $40(55 \%)$ had made no disclosure of any kind to their employers; seven out of $40(17 \%)$ had mentioned their seizures, often using a more neutral word like 'attacks' or 'turns', but not the diagnosis of epilepsy; and 11 out of $40(28 \%)$ had specifically informed their employers that they suffered from epilepsy. Of the seven who mentioned only their seizures, two did so when they applied for the job and five while at work. Of the 11 who, in addition, disclosed the diagnosis of epilepsy, five did so at the time of applying for the job, one immediately on arrival at work, and five after settling in. Thus, only seven of the 40 made any remarks at all about their condition before being appointed; and it was interesting that those seven people included three of the four employed persons suffering from either generalised or partial seizures more often than monthly.

We also have data on the circumstances in which disclosures were made. Considering again the seven people who disclosed only their seizures, two did so voluntarily, three were prompted to do so by circumstances (for example, after being questioned about absence from work), and one was 'required' to disclose after being confronted with a medical form. Of the 11 who told their employers that they suffered from epilepsy, five did so voluntarily, one was prompted to do so by circumstances, two were 'required' to disclose, and three disclosed only after a witnessed seizure at work. Social class seemed irrelevant to these configurations, but voluntary disclosure did appear to be associated with frequency of seizure; five out of seven $(71 \%)$ of those who volunteered information were suffering from more than one generalised and/or partial seizure a year, but only 11 out of $33(33 \%)$ of those who did not do so were suffering equivalently. Moreover, four out of seven $(57 \%)$ of those who disclosed voluntarily went on to have seizures at work, compared with only nine out of $33(27 \%)$ of those who did not. (It follows that just under one-third of those currently in full-time employment have had a seizure at work). Only two people made voluntary disclosures before they actually started work: one was having generalised and the other partial seizures daily at the time when they were accepted, and both went on to have seizures in the workplace. Table 1 shows the overall picture.

\section{PERCEIVED AND REAL DISCRIMINATION}

We wanted to know whether people thought they had been discriminated against as a result of their epilepsy. Significantly, although in the course of the interviews nearly $90 \%$ of the total sample made a general and unprovoked reference to epilepsy as a stigmatising condition, only one-third of those who did so could give details of even one incident when they had suspected another individual of stigmatising them (that is, of ridiculing, shunning, or otherwise 'unfairly' discriminating against them solely on the grounds of their epilepsy). Moreover, only 15 people, or $23 \%$ of the 66 in the sample with experience of full-time work post-onset, recollected such an incident occurring at work. Clearly, however, stigmatisation at work is neither a necessary nor a sufficient condition of an inhibited career. It is not a necessary condition because it is possible, for example, for discrimination against an epileptic to have dire consequences for his career and yet to be both 'fair' and sensible-for example, when restrictions are introduced on driving or operating complex machinery; and it is not a sufficient condition because it is possible for stigmatisation to occur without adversely affecting the victim's career. We were particularly interested, therefore, in the broader question of the extent to which the 66 people with post-onset work experience felt that their careers had been inhibited by any kind of negative discrimination based on their epilepsy.

Twenty-eight out of $66(42 \%)$ thought that their careers had been inhibited in one or more ways. Table 2 gives details of the types of inhibition reported and of the relative significance of stigmatisation. For example, nine people felt they had been rejected for one or more jobs because of their epilepsy, and four of the nine felt that they had encountered stigmatisation in this context: they had been 'unfairly' discriminated against solely because they had epilepsy. Similarly, seven people claimed they had been sacked on one or more occasions as a result of their epilepsy, and four of the seven felt that

Table 1 Patterns of disclosure for those who were in full-time employment at the time of interview

\begin{tabular}{|c|c|c|c|c|}
\hline Nature of disclosure & Nos. & (\%) & $\begin{array}{l}\text { Nos. having a } \\
\text { seizure at work }\end{array}$ & (\%) \\
\hline No disclosure or no voluntary disclosure of seizures or epilepsy & 33 out of 40 & (83) & 9 out of 33 & (27) \\
\hline Voluntary disclosure of seizures or epilepsy & 7 out of 40 & (17) & 4 out of 7 & (57) \\
\hline Voluntary disclosure of seizures or epilepsy before starting work & 2 out of 40 & (5) & 2 out of 2 & (100) \\
\hline
\end{tabular}


Table 2 Types of career inhibition reported by the 66 people in the sample with experience of full-time work after the onset of their seizures

\begin{tabular}{|c|c|c|c|c|}
\hline Type of inhibition & $\begin{array}{l}\text { No. complaining } \\
\text { out of } 66\end{array}$ & (\%) & $\begin{array}{l}\text { No. complaining of } \\
\text { stigmatization out of } 66\end{array}$ & (\%) \\
\hline $\begin{array}{l}\text { Rejected job application } \\
\text { Loss of responsibility or income } \\
\text { Reduced chance of promotion } \\
\text { Dismissal } \\
\text { Withdrawal from work because of pressure by employer } \\
\text { Suspension } \\
\text { Sheltered employment }\end{array}$ & $\begin{array}{l}9 \\
8 \\
8 \\
7 \\
5 \\
2 \\
1\end{array}$ & $\begin{array}{r}(14) \\
(12) \\
(12) \\
(11) \\
(8) \\
(3) \\
(1)\end{array}$ & $\begin{array}{l}4 \\
2 \\
1 \\
4 \\
2 \\
1\end{array}$ & $\begin{array}{l}(6) \\
(3) \\
(1) \\
(6) \\
(3) \\
(1) \\
-\end{array}$ \\
\hline
\end{tabular}

they had been victims of stigmatisation at least once in being dismissed. In all, nine out of $66(14 \%)$ of those with post-onset work experience felt that their careers had been inhibited in one or more ways as a result of stigmatisation. There were no associations between the reporting of stigmatisation or inhibitions at work and 'current employment status, social class, or current frequency of seizures.

Perceived discrimination might not correspond to real discrimination. Our data on the latter are necessarily restricted, but it was possible to compare rates of dismissal before and after onset. Forty-seven people had had a total of 169 full-time jobs before the onset of their seizures, and three of these (6\%) had suffered four sackings. By contrast, 66 people had had 249 full-time jobs post-onset, and 18 of these (27\%) had been the victims of 36 dismissals. Thus, one dismissal occurred in every 40 jobs before onset, and one in every seven jobs after onset $(P<0 \cdot 001)$. We have no way of telling whether or not the post-onset sackings were associated with seizure frequency at the time; given that nearly one-third of those experiencing generalised seizures and one-half of those experiencing partial seizures said that their seizures tended to occur in clusters with periods of relative freedom, it is not surprising that no association was found between dismissal and maximal frequency of past seizures. There was a significant association, however, between being dismissed and residence in a working class household: 16 out of $46(35 \%)$ of those from working class households had been sacked once or more than once post-onset, compared with two out of $20(10 \%)$ of those from middle class households $(P=<0 \cdot 05)$.

\section{Discussion and conclusions}

Nearly all of the adult epileptics in our study recognised that epilepsy can impede careers. Probably because of this most of them took care to conceal their seizures, and even more so the diagnosis of epilepsy, from their employers or potential employers: less than $20 \%$ of those currently employed full-time had voluntarily disclosed anything at all to their employers, and only $5 \%$ had done so before starting work. Those suffering most frequently from seizures were more likely both to disclose and to have seizures at work. Just over two-fifths of those who had had full-time jobs after the onset of seizures claimed that their careers had been inhibited in various ways as a result of stigmatisation or of 'sensible' discrimination. These claims could not be checked, but it was discovered, contrary to the findings of Rodin and others, ${ }^{9}$ that those with seizures more often than monthly were significantly more likely to be unemployed, and that sackings were appreciably more common after onsep $\vec{N}$ than before. Social class was independentl $\bar{\phi}$ 응 associated with disadvantage in the labour market $\frac{0}{\sigma}$

These findings are susceptible to more than onte interpretation: a handful of empirical generalisations does not constitute a 'theory of disadvantage'. We would therefore like to submit for further testing onêे $\vec{\theta}$ particular interpretation which is, we believe congruent with most other reported findings. ${ }^{10}$ It is well known that people of working class status are especially vulnerable to difficulties in employment; as we found, they are more likely to be out of work and more liable to be dismissed than their middle class counterparts. In this context a high rate of epileptic activity can be the straw that breaks the camel's back. Whatever his social class, however, the epileptic can be thwarted on the labour market by his epilepsy only if (a) he is stigmatised by others in a position to affect his work opportunities, (b) he is subject to sensible discrimination, (c) he denies himself work opportunities by losing the will, with or without justification, to apply for, endure, or advance at, work, or (d) he is the victim of any combination of these. We would suggest that self-denial of opportunities is at least as important as either stigmatisation or sensible discrimination as a cause of $\frac{D}{2}$ employment difficulties. For example, self-denial of opportunities may well account for a considerable $N$ amount of the unemployment in the sample, especially among married women.

Paradoxically, in so far as self-denial of $\omega$ opportunities can be understood in terms of a fear of 
encountering stigmatisation or sensible discrimination, it can also be said to predispose to the concealment from employers of seizures and their diagnostic label. Non-disclosure, in turn, reduces the likelihood of stigmatisation or sensible discrimination. It may be that the fear of meeting with stigmatisation or sensible discrimination is realistically rooted in past experiences of either or both, but we suspect that more often it derives from mere prejudice among epileptics who feel that employers are ignorant of, and hostile towards, the condition and those who suffer from it. If so, this would account for the fact that relatively few misfortunes at the hands of employers were recalled by members of our sample. Blaxter has written of epilepsy in similar vein in her study of disability. ${ }^{11}$ This takes us well beyond the data we have presented, however, and invites further, preferably prospective, research work in the area.

We thank the people with epilepsy and the GPs who cooperated in this study, which was supported by the Epilepsy Research Fund of the British Epilepsy Association.
Reprints from Graham Scambler, Department of Academic Psychiatry, Wolfson Building, Middlesex Hospital, London W1N 8AA.

\section{References}

${ }^{1}$ Department of Health and Social Security. People with Epilepsy. London: HMSO, 1970.

${ }^{2}$ Office of Health Economics. Epilepsy in Society. London: Office of Health Economics, 1971.

${ }^{3}$ College of General Practitioners. A survey of the epilepsies in general practice. Br Med J 1960; ii: 416-22.

4 Jones J. Employment of epileptics. Lancet 1965; 2: 486-9.

${ }^{5}$ Hopkins A, Scambler G. How doctors deal with epilepsy. Lancet 1977; 1: 183-6.

- Central Statistical Office. Social Trends; 8. London: HMSO, 1978.

${ }^{7}$ Pond D, Bidwell B, Stein L. A survey of epileptics in 14 general practices. Folia Psychiatr Neurol Neurochir Neerlandica 1960; 63: 217-36.

${ }^{8}$ Hopkins A, Scambler G. The social implications of epilepsy. In: Peters D, ed. Advanced Medicine. Volume 12. London: Pitman Medical, 1976.

${ }^{9}$ Rodin E. The Prognosis of Patients with Epilepsy. Springfield: Thomas, 1968.

${ }^{10}$ MacIntyre I. Epilepsy and employment. Community Health 1976; 7: 195-204.

${ }^{11}$ Blaxter M. The Meaning of Disability. London: Heinemann, 1976. 